\title{
Assessment of skin-to-skin contact (SSC) during the postpartum stay and its determinant factors among mothers at public health institutions in Ethiopia
}

\author{
Asres Bedaso ${ }^{1 *}\left(\mathbb{D}\right.$, Emnet Kebede ${ }^{2}$ and Tariku Adamu ${ }^{3}$
}

\begin{abstract}
Objective: The study aimed at assessing skin-to-skin contact (SSC) during the postpartum stay and its determinant factors among mothers at public health institutions in Ethiopia.

Result: A total of 384 mothers-indexed newborns admitted in postnatal wards were interviewed. The prevalence of mothers' SSC practice to their newborns with in the first $1 \mathrm{~h}$ during the postpartum stay was $28.1 \%$. Mothers education (AOR $=18.23[95 \% \mathrm{Cl} 5.26,63.52])$, and number of ANC visits (AOR $=8.55[95 \% \mathrm{Cl} 1.05,69.54]$ ) were independently associated with SSC practice of mothers to their infants.
\end{abstract}

Keywords: Skin-to-skin contact, Determinants, Mothers, Postpartum stay, Ethiopia

\section{Introduction}

Early skin-to-skin contact (SSC) is defined as placing the naked baby, covered across the back with a warm blanket, prone on the mother's bare chest [1]. Skin-to-skin contact between mother and baby after birth reduces crying, improves mother-baby interaction, keeps the baby warmer, and helps women breastfeed successfully. Long-lasting SSC throughout the postpartum period is important to decrease the frequency of formula supplementation for breast feeding and it will improve acquisition of the maternal role $[1,2]$.

Regardless of the importance of early mother-newborn SSC immediately after birth, it has not been universally implemented as routine care for healthy term neonates, and separation of mothers and infants is common in many health facilities. [3].

According to UNICEF 2.9 million babies die each year within 28 days and the first $24 \mathrm{~h}$ after birth are the most risky period both for the child and the mother. In

*Correspondence: asresbedaso@gmail.com

1 School of Nursing, College of Medicine and Health Sciences, Hawassa University, Hawassa, SNNPR, Ethiopia

Full list of author information is available at the end of the article
Ethiopia, an approximate 84,400 new born die within the first month of birth, according to the Lancet Series of Every New-born [4].

Some low and middle-income countries are making significant improvement by providing training for midwifery and nurses professionals to address the poorest families with good quality care at birth, particularly for small or ill new-born. Ethiopia is dedicated in minimizing the under-five mortality rate to 68 deaths per 1000 live births by 2015 [5]. Nevertheless, as in other developing countries, the reduction is mainly a result of fewer deaths in children 1 to 59 months old, while neonatal (first 28 days of life) mortality has shown more modest reaching 37 deaths per 1000 live births in 2011 according to EDHS [6].

There has been many research surrounding early SSC hours after birth, but far less in assessing the practice after the first hours and throughout the hospital stay during postpartum period. The effect of early SSC shortly after birth is so influential that it appears to surely contribute for exclusive breast feeding and the quality of mother-baby interactions [7].

Therefore, identification of perceived barriers held by mothers is vital in order to conduct interventions to 
facilitate early SSC. It is possible that increasing SSC in the postpartum period may reduce the frequency of formula supplementation during their hospital admission, a practice that is strongly linked with decreased breast feeding duration [8-10].

For mothers, SSC reduced postpartum bleeding, decreased the time it took to expel the placenta, increased oxytocin levels, and decreased cortisol levels, resulting in happier childbirth experiences, improved bonding with newborns, and increased confidence in their ability to care for the newborn [11-13]. Also, it is found that a dose-dependent correlation between the duration of SSC with full-term newborns initiated within the first $3 \mathrm{~h}$ of child-birth and the establishment of exclusive breastfeeding [14].

The importance of SSC continues beyond the first hour. The longer and more often mothers and babies are on SSC in the hours and days after the birth, the greater the benefit to get [15]. A recent study reported that Skin to skin contact in the postpartum period may also minimize the occurrence of postpartum depression, a condition that adversely affects mother/baby bonding, [16]. Also, SSC immediately after birth, which lasts for at least an hour has positive effects like maintaining body temperature normal, maintains heart rate, respiratory rate and blood pressure normal, and more likely to breastfeed exclusively and breastfeed longer [17].

Therefore the study aimed to assess SSC during the Postpartum Stay and its determinant factors among mothers at public health institutions in Ethiopia.

\section{Main text \\ Methods}

\section{Study design, area and period}

Institutional based cross-sectional study design was employed among mothers who gave live births at public health institutions in four selected towns, Ethiopia. This study was carried out in Addis Ababa (Central Ethiopia), Bahir Dar (Amhara National Regional State), Shashemene (Oromia Regional State) and Pawi (Benshangule Gumuz National Regional State). This study comprised Addis Ababa at St. Paul's Hospital Medical Millennium College (SPHMMC). There are two referral hospitals and 38 health centers which provide maternal, newborn and child health $(\mathrm{MNCH})$ and delivery services to their catchment areas in all the selected study areas. The study was conducted from January 2016 to May 2017, in the four selected cities public health institutions of post-natal units.

\section{Source and study population}

Source population for this study was all mothers who gave a live birth at public health institutions. Study population were all mothers who gave live births and admitted at post-natal wards for at least for the first $6 \mathrm{~h}$ in the selected public health facilities during the study period and fulfill the inclusion criterion.

\section{Inclusion and exclusion criteria}

Mothers who gave singleton live births vaginally and admitted for at least the first $6 \mathrm{~h}$ post-natal period during data collection period were included in the study. Mothers who developed serious postpartum complications/ unconscious were excluded from the study.

\section{Sample size determination and sampling procedure}

Single Population proportion formula was used to calculate the sample size considering the following assumptions: 95\% confidence level, margin of error (0.05), $50 \%$ prevalence of early SSC since there is no previous research conducted on early SSC practice in Ethiopia. Considering $10 \%$ non response rate the final estimated sample size was 384 . Simple random sampling technique was employed to select public health institutions in the four selected study areas. A mother who gave live births and admitted in post-natal units during the first $6 \mathrm{~h}$ was taken proportionally from each selected health facilities post-natal wards.

Four of the health facilities were selected using simple random sampling technique. Study subjects were obtained proportionally to the client flow from each post-natal unit and all mothers who gave live births in the selected public health facilities during the data collection period was interviewed consecutively with convenience to respond until the predetermined sample size was obtained (Additional file 1).

\section{Instruments}

A structured interview questionnaire was adopted from different literatures and used to explore the objective of the study, which was prepared in English and translated into Amharic (local language).

\section{Data collection technique}

Data collection was conducted by trained data collectors from January 2016 to May 2017 in each selected public health facilities during working hours. After getting written consent from each mother, interview was conducted by trained Midwives in each post-natal units of the study site. Pre-test was done on $5 \%$ of the study participants. Additional modifications and adjustments of the questionnaire were made based on the results of the pre-test.

\section{Study variables}

Dependent variable SSC practice status of mothers during postpartum stay. 
Independent variables Socio-demographic characteristics of mothers: age, marital status, educational status, residence. Newborn characteristics: sex, weight and prematurity. Obstetric related characteristics: type of pregnancy, ANC follow-up, parity, type of delivery, birth attendant profession and type of health institution.

\section{Data analysis}

The data was entered using Epi-Info version 3.5.1, and exported to SPSS version 20 for analysis. SSC practice status was assessed by using self-report method and actual observation during data collection time. The association between variables to the outcome variable was measured by OR with $95 \%$ confidence interval. The strength of statistical association was measured by adjusted odds ratios and $95 \%$ confidence intervals. Statistical significance was declared at $\mathrm{P}<0.05$ and variables which showed statistical significant association $(\mathrm{P}<0.2)$ during the bi-variate logistic regression was included in the final model.

\section{Result}

Mothers' and newborn's socio-demographic characteristics A total of 384 mothers of newborn were interviewed with $100 \%$ response rate. The mean age mothers' is 26.47 years $(\mathrm{SD} \pm 5.04)$ and $139(36.2 \%)$ mothers were between the ages of $25-29$ years and $72.9 \%$ of study participants were from urban areas (Table 1).

\section{Obstetrics Characteristics of Mothers}

From the total study participants 315 (82\%) of the pregnancy was unwanted and 348 (90.6\%) have ANC follow up at health facility (Table 2).

\section{Prevalence of mothers SSC practice}

All (384) mothers were observed to look whether their infants attached with their body (skin), and about 154 (40.1\%) of newborns were kept skin-to-skin with their mothers. Mothers were asked to indicate whether they provide SSC to their newborns during their postpartum stay for at least $1 \mathrm{~h}$, and only 108 (28.1\%) of mothers have practiced (Additional file 2).

\section{Benefits of SSC}

Among mothers who were asked about the advantages of SSC; 214 (55.7\%) of mothers have responded as they know the purpose of SSC, and 170 (44.3\%) of mothers didn't know. Among mothers who know SSC importance 88 (22.9\%) of them replied that SSC helps both to prevent hypothermia and facilitates EBF; 73 (19\%) knew as it prevents hypothermia; only $53(13.8 \%)$ of mothers said that SSC increases 'Mother-Infant' bonding.

\section{Mothers' reasons for not practicing SSC to their newborns}

Mothers who didn't practice SSC to their indexed infants also responded to a question about their reasons not to practice SSC to their newborns. About 126 (32.8\%) of them replied that it was due to embarrassment (Additional file 3).

\section{Factors associated with mothers SSC practice to their newborns}

Binary logistic regression model showed that educational status, Occupation, Type of current pregnancy and numbers of ANC visits of mothers were associated with SSC practice of mothers to their newborns. Also, Mothers whose current pregnancy is unplanned, mothers who had attended ANC visits, gestational age of current pregnancy of mothers, mothers' current birth attendant by health officer were significantly associated with SSC practice to their newborns (Table 3).

As it was clearly shown on the multivariable logistic regression analysis, after controlling for the effects of confounding variables, only two variables were significantly associated with mothers SSC practice to their newborns; educational status (AOR $=18.23$ [95\% CI 5.26, 63.52]), and number of $\mathrm{ANC}$ visits (AOR $=8.55[95 \% \mathrm{CI}$ $(1.05,69.54)]$ were significantly associated with SSC practice of mothers to their newborns (Table 3).

\section{Discussion}

It is well documented that continuous uninterrupted SSC, which lasts for at least an hour has been shown to improve the success of EBF, maintains body temperature normal, maintains heart rate, respiratory rate and blood pressure normal $[10,17]$.

The prevalence of SSC Practice amongst mothersinfants indexed during the postpartum stay in this study was $28.1 \%$. This finding was low as compared to studies in high-income countries in which SSC practice rate ranges from 60 to $70 \%$. The prevalence of SSC in this study was lower as compared to developed countries. The variation might be due to mothers' poor educational status (50\%), $44.3 \%$ of mothers didn't know SSC practice merits, and mothers were also lack knowledge and skills (31\%) on how to provide SSC in the present study.

In this study, from mothers who didn't practice SSC to their indexed infants about $32.8 \%$ of them put their reasons for not providing SSC to their newborns due to discomfort and lack of SSC knowledge and skills (31\%).

This result was in line with the study conducted in Canada and northern Midwest United States, which showed about $20-30 \%$ of mothers interrupted breast feeding to 
Table 1 Mothers' with their indexed babies' characteristics of SSC practice status during postpartum stay at public health institutions in four selected cities post-natal units, Ethiopia, 2016/17

\begin{tabular}{|c|c|c|c|c|c|c|}
\hline \multirow[t]{3}{*}{ Variables } & \multirow[t]{3}{*}{ Frequency } & \multirow[t]{3}{*}{ Percent } & \multicolumn{4}{|c|}{ SSC status $(\mathrm{N}=384)$} \\
\hline & & & \multicolumn{2}{|c|}{ Yes $(n=108)$} & \multicolumn{2}{|c|}{ No $(n=276)$} \\
\hline & & & $\mathbf{n}$ & $\%$ & $n$ & $\%$ \\
\hline \multicolumn{7}{|l|}{ Age } \\
\hline $16-20$ & 25 & 6.5 & 6 & 24.0 & 19 & 76.0 \\
\hline $21-24$ & 105 & 27.3 & 37 & 35.2 & 68 & 64.8 \\
\hline $25-29$ & 139 & 36.2 & 40 & 22.8 & 99 & 71.2 \\
\hline $30-34$ & 79 & 20.6 & 18 & 22.8 & 61 & 77.2 \\
\hline$>35$ & 36 & 9.4 & 7 & 19.4 & 29 & 80.6 \\
\hline \multicolumn{7}{|l|}{ Residence } \\
\hline Urban & 280 & 72.9 & 100 & 35.7 & 180 & 64.3 \\
\hline Rural & 104 & 27.1 & 8 & 7.7 & 96 & 92.3 \\
\hline \multicolumn{7}{|l|}{ Religion } \\
\hline Orthodox & 249 & 64.8 & 76 & 30.5 & 173 & 69.5 \\
\hline Muslim & 73 & 19.0 & 19 & 26.0 & 54 & 74.0 \\
\hline Protestant & 49 & 12.8 & 11 & 22.4 & 38 & 77.6 \\
\hline Catholic & 13 & 3.4 & 2 & 15.4 & 11 & 84.6 \\
\hline \multicolumn{7}{|l|}{ Ethnicity } \\
\hline Amhara & 228 & 59.4 & 74 & 32.5 & 154 & 67.5 \\
\hline Tigray & 40 & 10.4 & 8 & 20.0 & 32 & 80.0 \\
\hline Oromo & 116 & 30.2 & 26 & 22.4 & 90 & 77.6 \\
\hline \multicolumn{7}{|l|}{ Marital status } \\
\hline Single & 32 & 8.3 & 5 & 15.6 & 27 & 84.4 \\
\hline Married & 333 & 86.7 & 100 & 30.0 & 233 & 70.0 \\
\hline Divorced & 19 & 4.9 & 3 & 15.8 & 16 & 84.2 \\
\hline \multicolumn{7}{|l|}{ Educational status } \\
\hline Unable to read and write & 73 & 19.0 & 4 & 5.5 & 69 & 94.5 \\
\hline Primary (1-8) & 119 & 31.0 & 25 & 21.0 & 84 & 79.0 \\
\hline Secondary (9-12) & 113 & 29.4 & 45 & 39.8 & 68 & 60.2 \\
\hline Tertiary (Diploma and above) & 79 & 20.6 & 34 & 43.0 & 45 & 57.0 \\
\hline \multicolumn{7}{|l|}{ Occupation } \\
\hline Housewife & 261 & 68.0 & 73 & 28.0 & 188 & 72.0 \\
\hline Employed & 90 & 23.4 & 32 & 35.6 & 58 & 64.4 \\
\hline Unemployed & 33 & 8.6 & 3 & 9.1 & 30 & 90.9 \\
\hline \multicolumn{7}{|l|}{ Newborns weight (in grams) } \\
\hline$\geq 4000$ & 10 & 2.6 & 4 & 40.0 & 6 & 60.0 \\
\hline 2500-3999 & 346 & 90.1 & 90 & 26.0 & 256 & 74.0 \\
\hline $1500-2499$ & 27 & 7.0 & 13 & 48.1 & 14 & 51.9 \\
\hline $1000-1499$ & 1 & 0.3 & 1 & 100.0 & 0 & 0.0 \\
\hline \multicolumn{7}{|l|}{ Sex } \\
\hline Male & 203 & 52.9 & 54 & 26.6 & 149 & 73.4 \\
\hline Female & 181 & 47.1 & 54 & 29.8 & 127 & 70.2 \\
\hline
\end{tabular}

their newborns due to discomfort during the postpartum stay $[16,18]$. The reason for this might be around $25 \%$ of mothers in this study experienced instrumental delivery during their delivery which might prevent to provide SSC to their newborns because of the pain they develop.
SSC practice of mothers to their newborns is associated with their educational status. Illiterate mothers were 18 times more to practice SSC to their infants relative to their counterparts with mothers attended tertiary education $(\mathrm{AOR}=18.23$ [95\% CI 5.26, 63.52]). These results 
Table 2 Obstetric characteristics of mothers indexed infants on SSC practice status during postpartum stay at public health institutions in four selected cities post-natal units, Ethiopia, 2016/17

\begin{tabular}{|c|c|c|c|c|c|c|}
\hline \multirow[t]{3}{*}{ Variables } & \multirow[t]{3}{*}{ Frequency } & \multirow[t]{3}{*}{ Percent } & \multicolumn{4}{|c|}{ SSC status $(\mathrm{N}=384)$} \\
\hline & & & \multicolumn{2}{|c|}{ Yes $(n=108)$} & \multicolumn{2}{|c|}{ No $(n=276)$} \\
\hline & & & $\mathbf{n}$ & $\%$ & $\bar{n}$ & $\%$ \\
\hline \multicolumn{7}{|l|}{ Type of current pregnancy } \\
\hline Wanted/planned & 315 & 82.0 & 99 & 31.4 & 216 & 68.6 \\
\hline Unwanted/unplanned & 69 & 18.0 & 9 & 13.0 & 60 & 87.0 \\
\hline \multicolumn{7}{|l|}{ ANC follow up } \\
\hline Yes & 348 & 90.6 & 107 & 30.7 & 241 & 69.3 \\
\hline No & 36 & 9.4 & 1 & 2.8 & 35 & 97.2 \\
\hline \multicolumn{7}{|l|}{ Number of ANC visits } \\
\hline One & 17 & 4.4 & 1 & 5.9 & 16 & 94.1 \\
\hline Two & 32 & 8.3 & 7 & 21.9 & 25 & 78.1 \\
\hline Three & 67 & 17.4 & 15 & 22.4 & 52 & 77.6 \\
\hline Four & 232 & 60.4 & 84 & 36.2 & 148 & 63.8 \\
\hline \multicolumn{7}{|l|}{ GA (gestational age) } \\
\hline$<37$ weeks & 9 & 2.3 & 7 & 77.8 & 2 & 22.2 \\
\hline 37-42 weeks & 375 & 97.7 & 101 & 26.9 & 274 & 73.1 \\
\hline \multicolumn{7}{|l|}{ Parity } \\
\hline Primi para & 139 & 36.2 & 47 & 33.8 & 92 & 66.2 \\
\hline Multi para & 245 & 63.8 & 61 & 24.9 & 184 & 75.1 \\
\hline \multicolumn{7}{|l|}{ Current birth attendant } \\
\hline Midwife & 274 & 71.4 & 88 & 32.1 & 186 & 67.9 \\
\hline Nurse & 30 & 7.8 & 6 & 20.0 & 24 & 80.0 \\
\hline Doctor & 25 & 6.5 & 6 & 24.0 & 19 & 76.0 \\
\hline Health officer & 55 & 14.3 & 8 & 14.5 & 47 & 85.5 \\
\hline \multicolumn{7}{|l|}{ Mode of delivery } \\
\hline Normal SVD & 292 & 76.0 & 103 & 35.3 & 189 & 64.7 \\
\hline Assisted delivery & 66 & 17.2 & 5 & 7.6 & 61 & 92.4 \\
\hline Abdominally (C/S) & 26 & 6.8 & 0 & 0.0 & 26 & 100.0 \\
\hline \multicolumn{7}{|l|}{ Time after delivery } \\
\hline$<6 \mathrm{~h}$ & 295 & 76.8 & 77 & 26.1 & 218 & 73.9 \\
\hline $6-12 \mathrm{~h}$ & 50 & 13.0 & 16 & 32.0 & 34 & 68.0 \\
\hline$>12 \mathrm{~h}$ & 39 & 10.2 & 15 & 38.5 & 24 & 61.5 \\
\hline
\end{tabular}

could be explained that since majority of mothers in this study were housewives $(68 \%)$ and they pass all their time with their newborns and feed their breast milk while employed mothers were mostly unable to do this.

Numbers of ANC visits was significantly associated with mothers SSC practice to their newborns during the postpartum stay. Mothers who had attended ANC visits three times were 8 times more likely to provide SSC to their newborns as compared to those who had attended only their first visit $(\mathrm{AOR}=8.55$ [95\% CI 1.05, 69.54] ). This could be explained that when mothers attended more ANC visits, their awareness will increase (more than half (55.7\%) of mothers have good knowledge on the purpose of SSC) and adherence to care for them and the newborn become more effective, this results low compliance, and finally leads mothers to provide SSC to their newborns.

\section{Conclusion}

This study revealed that the proportion of mothers' SSC practice for at least $1 \mathrm{~h}$ to their indexed newborns' during the postpartum stay was better $(28.1 \%)$ as compared to other settings.

\section{Limitations}

The cross sectional nature of the present study prevents any causal inferences. 
Table 3 Bivariate and multivariable logistic regression analysis of mothers SSC practice and its determinant factors during postpartum stay at public health institutions in four selected towns' post natal units, Ethiopia, 2016/17

\begin{tabular}{|c|c|c|c|c|c|c|c|c|}
\hline \multirow[t]{3}{*}{ Variables } & \multicolumn{4}{|c|}{ SSC status $(\mathrm{N}=384)$} & \multirow[t]{3}{*}{$\operatorname{COR}(95 \% \mathrm{Cl})$} & \multirow[t]{3}{*}{ P-value } & \multirow[t]{3}{*}{ AOR $(95 \% \mathrm{Cl})$} & \multirow[t]{3}{*}{ P-value } \\
\hline & \multicolumn{2}{|c|}{ Yes $(n=81)$} & \multicolumn{2}{|c|}{ No $(n=150)$} & & & & \\
\hline & $\mathrm{n}$ & $\%$ & $\mathrm{n}$ & $\%$ & & & & \\
\hline \multicolumn{9}{|l|}{ Educational status } \\
\hline Unable to read and write & 4 & 5.5 & 69 & 94.5 & $13.03(4.33,39.23)$ & 0.000 & $18.23(5.26,63.52)$ & $0.000^{*}$ \\
\hline Primary (1-8) & 25 & 21.0 & 84 & 79.0 & $2.84(1.52,5.32)$ & & $3.72(1.62,8.52)$ & \\
\hline Secondary (9-12) & 45 & 39.8 & 68 & 60.2 & $1.14(0.64,2.05)$ & & $1.59(0.75,3.39)$ & \\
\hline Tertiary (Diploma and above) & 34 & 43.0 & 45 & 57.0 & 1.00 & & 1.00 & \\
\hline \multicolumn{9}{|l|}{ Occupation } \\
\hline Housewife & 73 & 28.0 & 18 & 72.0 & 1.00 & & 1.00 & \\
\hline Employed & 32 & 35.6 & 858 & 64.4 & $0.70(0.42,1.17)$ & & $0.43(0.11,1.66)$ & \\
\hline Unemployed four & 3 & 9.1 & 30 & 90.9 & $3.88(1.15,13.12)$ & 0.029 & $67(0.16,2.83)$ & 0.582 \\
\hline \multicolumn{9}{|l|}{ Type of current pregnancy } \\
\hline Wanted/planned & 99 & 31.4 & 216 & 68.6 & 1.00 & & 1.00 & \\
\hline Unwanted/unplanned & 9 & 13.0 & 60 & 87.0 & $3.06(1.46,6.40)$ & 0.003 & $0.59(0.24,1.45)$ & 0.251 \\
\hline \multicolumn{9}{|l|}{ Number of ANC visits } \\
\hline One & 1 & 5.9 & 16 & 94.1 & 1.00 & & 1.00 & \\
\hline Two & 7 & 21.9 & 25 & 78.1 & $19.87(2.67,147.62)$ & & $9.97(1.21,81.91)$ & \\
\hline Three & 15 & 22.4 & 52 & 77.6 & $9.09(1.18,69.69)$ & 0.003 & $8.55(1.05,69.54)$ & $0.032^{*}$ \\
\hline Four & 84 & 36.2 & 148 & 63.8 & $2.03(0.84,4.88)$ & & $1.31(0.49,3.50)$ & \\
\hline \multicolumn{9}{|l|}{ GA (gestational age) } \\
\hline$<37$ weeks & 7 & 77.8 & 2 & 22.2 & 1.00 & & 1.00 & \\
\hline 37-42 weeks & 101 & 26.9 & 274 & 73.1 & $9.49(1.94,46.47)$ & 0.005 & $0.07(0.01,0.53)$ & $0.010^{*}$ \\
\hline \multicolumn{9}{|l|}{ Current birth attendant } \\
\hline Midwife & 88 & 32.1 & 186 & 67.9 & 1.00 & & 1.00 & \\
\hline Nurse & 6 & 20.0 & 24 & 80.0 & $1.89(0.75,4.79)$ & & $0.20(0.07,0.53)$ & \\
\hline Doctor & 6 & 24.0 & 19 & 76.0 & $1.49(0.58,3.88)$ & & $0.22(0.06,0.89)$ & \\
\hline Health officer & 8 & 14.5 & 47 & 85.5 & $2.78(1.26,6.13)$ & 0.011 & $0.28(0.07,1.09)$ & $0.212^{*}$ \\
\hline
\end{tabular}

COR crude odds ratio, $A O R$ adjusted odds ratio, $C l$ confidence interval

* Significant association with P-value $<0.05$

\section{Additional files}

Additional file 1. Schematic representation of the sampling procedure for the study on assessment of SSC during the postpartum stay and its determinants among mothers at public health institutions in four selected cities post-natal units, Ethiopia, 2016/17.

Additional file 2. Proportion of mothers SSC practice status to their indexed newborns during postpartum stay at public health institutions in four selected towns' post-natal units, Ethiopia, 2016/17.

Additional file 3. Mothers reasons for not providing SSC to their indexed newborns during postpartum stay at public health institutions in four selected towns' post-natal units, Ethiopia, 2016/17.

\section{Abbreviations}

ANC: ante natal care; BEmONC: basic emergency obstetric and newborn care; C/S: cesarean section; Cl: confidence interval; EBF: exclusive breast feeding; EDHS: Ethiopian Demographic Heath Survey; EMA: Ethiopian Midwife Association; EPHA: Ethiopian Public Health Association; FMoH: Federal Ministry of Heath; GA: gestational age; HC: health center; Kg: kilo gram; MNCH: maternal newborn and child health; SPHMMC: St. Paul's Hospital Medical Millennium
College; SPSS: statistical package for social science; SSC: skin to skin contact; SVD: spontaneous vaginal delivery; UNICEF: United Nations Children's Fund.

\section{Authors' contributions}

$A B, E K$, TA participated in the conception, design of the study, reviewing proposal and data analysis. $A B$ and EK participated in reviewing proposal and writing the research report. AB prepared the manuscript for publication. All authors read and approved the final manuscript.

\section{Author details}

${ }^{1}$ School of Nursing, College of Medicine and Health Sciences, Hawassa University, Hawassa, SNNPR, Ethiopia. ${ }^{2}$ Department of Midwifery, College of Medicine and Health Sciences, Hawassa University, Hawassa, SNNPR, Ethiopia. ${ }^{3}$ Department of Midwifery, College of Medicine and Health Science, Assosa University, Assosa, Ethiopia.

\section{Acknowledgements}

First and foremost, we would like to acknowledge the Ethio-Canada $\mathrm{MNCH}$ Project of Federal Ministry of Health (FMoH) Ethiopia which gave us an opportunity to engage and undertake this project. We are also grateful to our host institutions and staffs; where data collection undergone, for their facilitation during data collection period, and providing us the necessary information and cooperative support. Finally, our deepest gratitude also goes to the data 
collectors, supervisor and respondents without whom this project would not have been realized.

\section{Competing interests}

The authors declare that they have no competing interests.

\section{Availability of data and materials}

All relevant data are included in this article and its supporting document.

\section{Consent for publication}

Not applicable.

\section{Ethics approval and consent to participate}

Ethical clearance was obtained from the Ethical Committee of St Paul's Hospital Millennium Medical College (SPHMMC). Officials from each selected region/town health offices were communicated through formal letters which was obtained from SPHMMC. An official letter also secured to all the selected health facilities. Before interviewing, written consent was obtained from each study participant mothers. They were informed about the purpose and objective of the study. They were also informed that, they have the right to discontinue or refuse to participate in the study. Confidentiality of information and privacy was also maintained.

\section{Funding}

No funding was received for this research work.

\section{Publisher's Note}

Springer Nature remains neutral with regard to jurisdictional claims in published maps and institutional affiliations.

Received: 18 December 2018 Accepted: 11 March 2019 Published online: 14 March 2019

\section{References}

1. Moore ER, Anderson GC, Bergman N, Dowswell T. Early skin-to-skin contact for mothers and their healthy newborn infants. Cochrane Database Syst Rev. 2012;5:CD003519. https://doi.org/10.1002/14651858.cd003519. pub3.

2. Dalbye R, Calais E, Berg M. Mothers' experiences of skin-to-skin care of healthy full-term newborns: a phenomenology study. Sex Reprod Healthc. 2011;2(3):107-11. https://doi.org/10.1016/j.srhc.2011.03.003.

3. Service package of care for healthy neonate in hospital: Bureau of Neonatal Health, Office of Family and School Population Health, Ministry of Health and Medical Education. Persian: Winter; 2011.

4. The Lancet Series of Every New-born. http://press.Thelancet.com/ENSer iesLancetRelease.pdf. http://www.thelancet.com/series/everynewborn.
5. Karim AM, Admassu K, Schellenberg J, Alemu H, Getachew N, et al. Effect of Ethiopia's health extension program on maternal and newborn health care practices in 101 rural districts: a dose-response study. PLoS ONE. 2013;8(6):e65160. https://doi.org/10.1371/journal.pone.0065160.

6. CSA and ICF International. Ethiopia demographic and health survey 2011. Addis Ababa: Central Statistical Agency and ICF International; 2012.

7. Bystrova K, Ivanova V, Edhborg M, Matthiesen AS, Ransjö-Arvidson AB, Mukhamedrakhimov R, Widström AM. Early contact versus separation: effects on mother-infant interaction one year later. Birth. 2009;36(2):97109. https://doi.org/10.1111/j.1523-536X.2009.00307.

8. DiGirolamo, Grummer-Stawn, \& Fein, 2008; Murray, Ricketts, \& Dellaport, 2007; Parry, Ip, Chau, Wu, \& Tarrant, 2013; Semenic, Loiselle, \& Gottlieb, 2008.

9. Beyond survival: integrated delivery care practices for long-term maternal and infant nutrition, health and development. 2nd ed. Washington, DC: PAHO; 2013. https://www.who.int/nutrition/.../infantfeeding/BeyondSurv ival_2nd_edition_en.pdf?u.

10. Ferrarello D, Hatfield L. Barriers to skin-to-skin care during the postpartum stay. Am J Matern Child Nurs. 2014;39(1):57-60. https://doi. org/10.1097/01.NMC.0000437464.31628.3d.

11. Galligan M. Proposed guidelines for skin-to-skin treatment of neonatal hypothermia. MCN Am J Matern Child Nurs. 2006:31:298-304.

12. McCall EM, Alderdice F, Halliday HL, Jenkins JG, Vohra S. Interventions to prevent hypothermia at birth in preterm and/or low birth-weight infants. Cochrane Database Syst Rev. 2010;17:CD004210.

13. Ludington-Hoe SM, Morgan K, Abouefettoh A. A clinical guideline for implementation of kangaroo care with premature infants of 30 weeks' postmenstrual age. Adv Neonatal Care. 2008;8(3 Suppl):S3-23.

14. Bramson L, Lee JW, Moore $E$, et al. Effect of early skin-to-skin motherinfant contact during the first 3 hours following birth on exclusive breastfeeding during the maternity hospital stay. JHumLact. 2010;26:130-7 (Epub 2010 Jan 28)

15. Moore ER, Anderson GC. Randomized controlled trial of very early mother-infant skin-to-skin contact and breastfeeding status. J Midwifery Women's Health. 2007;52(2):116-25.

16. Bigelow A, Power M, MacLellan-Peters J, Alex M, McDonald C. Effect of mother/infant skin-to-skin contact on postpartum depressive symptoms and maternal physiological stress. J Obstet Gynecol Neonatal Nurs. 2012;41(3):369-82. https://doi.org/10.1111/j.1552-6909.2012.01350.

17. Svensson KE, Velandia MI, Matthiesen AS, Welles-Nyström BL, Widström AM. Effects of mother-infant skin-to-skin contact on severe latch-on problems in older infants: a randomized trial. Int Breastfeed J. 2013;8(1):1. https://doi.org/10.1186/1746-4358-8-1.

18. Morrison B, Ludington-Hoe S, Anderson GC. Interruptions to breastfeeding dyads on postpartum day 1 in a university hospital. J Obstet Gynecol Neonatal Nurs. 2006;35(6):709-16. https://doi.org/10.111 1/j.1552-6909.2006.00095.
Ready to submit your research? Choose BMC and benefit from:

- fast, convenient online submission

- thorough peer review by experienced researchers in your field

- rapid publication on acceptance

- support for research data, including large and complex data types

- gold Open Access which fosters wider collaboration and increased citations

- maximum visibility for your research: over 100M website views per year

At BMC, research is always in progress.

Learn more biomedcentral.com/submissions 